\title{
Association between afterhours admission to the intensive care unit, strained capacity, and mortality: a retrospective cohort study
}

\author{
Adam M. Hall ${ }^{1}$, Henry T. Stelfox ${ }^{2,3}$, Xioaming Wang ${ }^{4}$, Guanmin Chen ${ }^{4}$, Danny J. Zuege ${ }^{2}$, Peter Dodek ${ }^{5}$,
} Allan Garland ${ }^{6}$, Damon C. Scales ${ }^{7}$, Luc Berthiaume ${ }^{2}$, David A. Zygun ${ }^{1,3}$ and Sean M. Bagshaw ${ }^{1,3^{*}}$

\begin{abstract}
Background: Admission to the intensive care unit (ICU) outside daytime hours has been shown to be variably associated with increased morbidity and mortality. We aimed to describe the characteristics and outcomes of patients admitted to the ICU afterhours (22:00-06:59 h) in a large Canadian health region. We further hypothesized that the association between afterhours admission and mortality would be modified by indicators of strained ICU capacity.

Methods: This is a population-based cohort study of 12,265 adults admitted to nine ICUs in Alberta from June 2012 to December 2014. We used a path-analysis modeling strategy and mixed-effects multivariate regression analysis to evaluate direct and integrated associations (mediated through Acute Physiology and Chronic Health Evaluation (APACHE) II score) between afterhours admission (22:00-06:59 h) and ICU mortality. Further analysis examined the effects of strained ICU capacity and varied definitions of afterhours and weekend admissions. ICU occupancy $\geq 90 \%$ or clustering of admissions ( $\geq 0.15$, defined as number of admissions $2 \mathrm{~h}$ before or after the index admission, divided by the number of ICU beds) were used as indicators of strained capacity.

Results: Of 12,265 admissions, 34.7\% ( $n=4251)$ occurred afterhours. The proportion of afterhours admissions varied amongst ICUs (range 26.7-37.8\%). Patients admitted afterhours were younger (median (IQR) 58 (44-70) vs 60 (47-70) years, $p<0.0001)$, more likely to have a medical diagnosis $(75.9 \%$ vs $72.1 \%, p<0.0001)$, and had higher APACHE II scores (20.9 (8.6) vs 19.9 (8.3), $p<0.0001)$. Crude ICU mortality was greater for those admitted afterhours (15.9\% vs $14.1 \%, p=0$. 007), but following multivariate adjustment there was no direct or integrated effect on ICU mortality (odds ratio (OR) 1. 024; $95 \%$ confidence interval (Cl) $0.923-1.135, p=0.658$ ). Furthermore, direct and integrated analysis showed no association of afterhours admission and hospital mortality $(p=0.90)$ or hospital length of stay (LOS) $(p=0.27)$, although ICU LOS was shorter $(p=0.049)$. Early-morning admission (00:00-06:59 h) with ICU occupancy $\geq 90 \%$ was associated with short-term ( $\leq 7$ days) and all-cause ICU mortality.
\end{abstract}

Conclusions: One-third of critically ill patients are admitted to the ICU afterhours. Afterhours ICU admission was not associated with greater mortality risk in most circumstances but was sensitive to strained ICU capacity.

Keywords: Intensive care unit, Afterhours admission, ICU mortality, APACHE II score

\footnotetext{
* Correspondence: bagshaw@ualberta.ca

'Department of Critical Care Medicine, Faculty of Medicine and Dentistry, University of Alberta and Alberta Health Services, 2-124E Clinical Sciences Building, 8440-112 ST NW, Edmonton T6G 2B7, Canada

${ }^{3}$ Critical Care Strategic Clinical Network, Alberta Health Services, Edmonton,

Canada

Full list of author information is available at the end of the article
}

(C) The Author(s). 2018 Open Access This article is distributed under the terms of the Creative Commons Attribution 4.0 International License (http://creativecommons.org/licenses/by/4.0/), which permits unrestricted use, distribution, and reproduction in any medium, provided you give appropriate credit to the original author(s) and the source, provide a link to the Creative Commons license, and indicate if changes were made. The Creative Commons Public Domain Dedication waiver (http://creativecommons.org/publicdomain/zero/1.0/) applies to the data made available in this article, unless otherwise stated. 


\section{Background}

Patients may suffer clinical deterioration and develop critical illness at unpredictable times, commonly outside conventional daytime hours. The importance of early resuscitation in critical illness is well described. Adequate early resuscitation can improve outcomes in sepsis [1], vascular emergencies [2-5], trauma [6], and cardiac arrest $[7,8]$. As such, improving outcomes for critically ill patients necessitates that critical care services be accessible $24 \mathrm{~h}$ a day and 7 days a week [9-11].

While numerous organizational factors likely influence access to critical care services and outcomes for critically ill patients, prior studies have suggested that intensive care unit (ICU) admission occurring outside conventional work hours [12-16] or on weekends $[17,18]$ is associated with greater risk for major morbidity and mortality. Prior data on this issue have been discordant, with some studies reporting increased risk of mortality for ICU admission occurring afterhours [19], while others, including two recent systematic reviews [20,21], suggested no incremental hazard.

The association between patient outcomes and afterhours ICU admission may be partly influenced by ICU organizational factors (i.e., staffing models, capacity) that are not patient related, and as such may be highly variable across health systems. Knowledge of avoidable ICU organization issues that may impact patient care and outcome, such as the effect of time of ICU admission, are important to understand to enable health system improvement, to guide procedure and policy development, and for workplace and capacity planning.

We hypothesized, in part due to data suggesting that critical care services in our large health region commonly experience strained capacity [22], that patients admitted to the ICU afterhours would suffer greater risk for death compared with daytime hours, and that this association would be modified by indicators of strained capacity. Accordingly, we performed a population-based study to evaluate the association between afterhours ICU admission and mortality among adult critically ill patients.

\section{Methods}

This study was approved by the Human Research Ethics Board at the University of Alberta prior to commencement (File \# Pro00046184). The need for written informed consent was waived.

\section{Study design, setting, and population}

This was a population-based cohort study utilizing routinely captured data evaluating all adult (age $\geq 15$ years) patients $(n=12,265)$ admitted to nine ICUs (median (IQR) number of ICU beds $24(18-28)$ ) in Alberta, Canada, from June 2012 to December 2014. All ICUs were mixed medical/surgical units in two major cities:
Calgary (four units) and Edmonton (five units). Of these, two were classified as academic/quaternary, two as academic/tertiary, and five as metropolitan/community ICUs. All included ICUs utilized a "closed" model and were staffed by certified intensivists, who were present during the daytime hours each day and available afterhours on call, with supplemental in-house coverage by clinical associates or resident trainees.

\section{Data sources}

Data were analyzed from eCritical Alberta, a provincial clinical information system, data warehouse, and clinical analytics system [22]. eCritical is a bedside interdisciplinary electronic documentation system (MetaVision ${ }^{\mathrm{TM}}$; iMDsoft) which captures demographic, diagnostic/casemix (i.e., comorbidity, diagnostic classification, surgical status, Acute Physiology and Chronic Health Evaluation (APACHE) II and III score), laboratory, and device (physiologic monitors, ventilators, renal replacement therapy, use of vasoactive medications) data. TRACER is a comprehensive, multimodal, and integrated data repository and clinical analytics system. The eCritical Alberta program includes rigorous methods of data quality assurance, including auditing of high value data. eCritical systems have been used previously to facilitate health services research [22-24]. Missing data in our cohort were uncommon $(<3 \%$ for any data variable included in the analyses). For our primary exposure (afterhours admission) and primary outcome (ICU mortality), there were no missing data elements.

\section{Main exposures and outcomes}

The primary exposure was ICU admission afterhours, defined as occurring between 22:00 and 06:59 h. The primary outcome was ICU mortality. Secondary outcomes included ICU mortality within 30 h, 3 days, and 7 days following admission, in-hospital mortality, and ICU and hospital length of stay (LOS). Other study variables included age, sex, case mix (e.g., diagnostic classification, surgical status, comorbidities, and Charlson comorbidity index), admission source (i.e., emergency department (ED), operating theater (OR), hospital ward), and ICU site (i.e., location, hospital type). The associations between afterhours admission and mortality were further evaluated with indicators of strained ICU capacity, including instantaneous bed occupancy at ICU admission [22], and clustering of admissions (quantified by number of admissions $2 \mathrm{~h}$ before or after the index admission, divided by the number of funded ICU beds).

\section{Statistical methods Descriptive analysis}

Data were initially explored descriptively. Normally or near normally distributed data, confirmed by histogram, 
are reported as means with standard deviations (SDs) and compared by Student's $t$ test. Nonnormally distributed continuous data are reported as medians with interquartile ranges (IQRs) and were compared by Wilcoxon-Mann-Whitney $U$ test. Categorical variables were compared using the chi-squared test.

\section{Path-analysis modeling}

Additional file 1 outlines our mediation analysis model of the direct and indirect (mediated through APACHE II score) relationship between afterhours admission and ICU mortality. First, we estimated the association between afterhours admission and APACHE II score by a randomeffects multivariate linear regression model, adjusted for demographics (e.g., age, sex), Charlson comorbidity index, case mix (e.g., diagnostic classification, surgical status), instantaneous bed occupancy at ICU admission, and ICU site (e.g., location, hospital type) (Additional file 2). We assumed that intercepts for each of the nine ICU sites were random, implying that different ICUs have different illness severity levels. This model allows calculation of the association between afterhours admission and APACHE II scores. We then estimated the effects of afterhours admission and APACHE II score on ICU mortality by a random-effects multivariate logistic regression model (Additional files 3, 4, 5, 6, 7, and 8). ICU type was again used as random-effects predictor, and the model was similarly adjusted as in the linear model. Customized variable selection was adopted to produce sparse models for the multivariate modeling analyses [25]. All of the modeling analyses were conducted in SAS (release 9.4; SAS Institute, Cary, NC, USA). Lastly, simulation experiments (1 million replicates) were conducted in R Core [26] to estimate the total combined effect by integrating both the direct and indirect effects of afterhours admission on ICU mortality. Random-effects multivariate Poisson regression was used to evaluate the association between afterhours admission, APACHE II score, and hospital LOS (Additional file 9).

\section{Sensitivity analysis}

Sensitivity analysis was performed using the same pathanalysis model with modified definitions of afterhours admission including the following: early morning admission, defined as 00:00-06:59 h; early morning admission on a weekend or statutory holiday (non-work day); early morning admission in winter (October-March); early morning admission with high bed occupancy ( $\geq 90 \%, \geq 95 \%)$, and afterhours admission with clustering of admissions.

\section{Results}

Afterhours ICU admission

Of 12,265 admissions to the nine ICUs, $34.7 \%(n=4251)$ occurred afterhours. Afterhours admission was most common in academic units (Table 1). There was significant variability across units (range 26.7-37.8\%; Figure 1). Most afterhours admissions were referred from the ED (46.4\%), hospital ward (27.1\%), and operating theater (16. 9\%), respectively. Afterhours admissions were also associated with greater occupancy, but less clustering of ICU admissions. Of afterhours admissions, 30.6\% $(n=1302)$ were admitted on weekends/holidays, $47.0 \% \quad(n=1998)$ were during winter months (October-March), while 70. $9 \% \quad(n=3016)$ were between 00:00 and 06:59 h, respectively. Patients admitted afterhours were younger, mostly nonoperative, and had greater APACHE II scores (Table 2).

\section{Association between afterhours admission and APACHE II score}

In multivariate analysis, afterhours admission was associated with significantly higher APACHE II scores (estimate (SE) 0.78 (0.13), $p<0.0001$ ) (Additional file 2). Female sex, emergent surgical admission, diagnostic category, and higher occupancy were also associated with higher APACHE II scores, while elective surgical status was associated with lower APACHE II scores.

Association between afterhours admission and ICU mortality ICU mortality was $14.7 \%(n=1800)$. Unadjusted ICU mortality was greater for afterhours compared with daytime hours admission (15.9\% vs 14.1\%; OR 1.15; 95\% CI 1.04-1.28, $p=0.007$ ) (Table 3; Figure 2). This effect was persistent across variable durations following ICU admission. However, after multivariate adjustment, there was no significant direct or integrated effect (mediated through APACHE II score) of afterhours admission on ICU mortality (Table 4).

Afterhours admissions had worse short-term outcomes in the presence of indicators of strained ICU capacity. For admissions occurring between 00:00 and 06:59 $\mathrm{h}$ and while bed occupancy was $\geq 90 \%$, ICU mortality was greater. Similarly, for afterhours admission occurring during relative clustering of ICU admissions, short-term ICU mortality (<7 days) was higher (Table 5 ).

\section{Association between afterhours admission and secondary outcomes}

Hospital mortality was $21.3 \%(n=2605)$ with no significant difference between afterhours and daytime ICU admission in unadjusted, direct, or integrated (mediated through APACHE II score) analyses (Tables 3 and 4). In multivariate analysis, afterhours compared with daytime ICU admission was associated with reduced ICU LOS in direct and integrated analysis; however, this was not significant when stratified by ICU survival status. There was no association with afterhours admission and hospital LOS. 
Table 1 Summary of ICU characteristics, stratified by time of ICU admission

\begin{tabular}{|c|c|c|c|c|}
\hline Characteristic & $\begin{array}{l}\text { Total } \\
(n=12,265,100 \%)\end{array}$ & Workhours $(n=8014,65.3 \%)$ & $\begin{array}{l}\text { Afterhours } \\
(n=4251,34.7 \%)\end{array}$ & $p$ value \\
\hline Location, $n(\%)$ & & & & 0.012 \\
\hline Calgary & $6732(54.9)$ & $4333(54.1)$ & $2399(56.4)$ & \\
\hline Edmonton & $5533(45.1)$ & $3681(45.9)$ & 1852 (43.6) & \\
\hline Hospital type & & & & 0.0009 \\
\hline Academic & $5776(47.1)$ & $3676(45.9)$ & $2100(49.4)$ & \\
\hline Tertiary & $3664(29.9)$ & $1895(23.7)$ & $930(21.9)$ & \\
\hline Community & $2825(23.0)$ & $2443(30.5)$ & $1221(28.7)$ & \\
\hline ICU, $n(\%)$ & & & & $<0.0001$ \\
\hline Academic 1 & $3083(25.1)$ & $1918(23.9)$ & $1165(27.4)$ & \\
\hline Community 1 & $333(2.7)$ & $233(2.9)$ & $100(2.4)$ & \\
\hline Community 2 & $303(2.5)$ & $222(2.8)$ & $81(1.9)$ & \\
\hline Tertiary 1 & $1728(14.1)$ & $1150(14.3)$ & $578(13.6)$ & \\
\hline Tertiary 2 & $1936(15.8)$ & $1293(16.1)$ & $643(15.1)$ & \\
\hline Community 3 & $1258(10.3)$ & $824(10.3)$ & $434(10.2)$ & \\
\hline Community 4 & $268(2.2)$ & $175(2.2)$ & $93(2.2)$ & \\
\hline Community 5 & $663(5.4)$ & $441(5.5)$ & $222(5.2)$ & \\
\hline Academic 2 & $2693(22.0)$ & $1758(21.9)$ & $935(22.0)$ & \\
\hline Number of ICU beds, median (IQR) & $24(18-28)$ & $24(10-28)$ & $25(18-28)$ & 0.0001 \\
\hline Admitted/transferred from & & & & $<0.0001$ \\
\hline Emergency department & $4823(39.3)$ & $2851(35.6)$ & $1972(46.4)$ & \\
\hline PACU/operating theater & $2398(19.6)$ & $1680(21.0)$ & $718(16.9)$ & \\
\hline Post procedure ${ }^{a}$ & $44(0.4)$ & $38(0.5)$ & $6(0.1)$ & \\
\hline Other critical care unit & $313(2.6)$ & $238(3.0)$ & $75(0.2)$ & \\
\hline Ward transfer & $3681(30.0)$ & $2528(31.5)$ & $1153(27.1)$ & \\
\hline Outside hospital & $428(3.5)$ & $268(3.3)$ & $160(3.8)$ & \\
\hline Other ${ }^{b}$ & $358(2.9)$ & $263(3.3)$ & $95(2.2)$ & \\
\hline Unspecified $^{c}$ & $221(1.8)$ & $149(1.9)$ & $72(1.7)$ & \\
\hline Admitted on weekend/holiday & $3471(28.3)$ & $2169(27.1)$ & $1302(30.6)$ & $<0.0001$ \\
\hline Admitted during winter (October-March) & $5799(47.3)$ & $3801(47.4)$ & $1998(47.0)$ & 0.66 \\
\hline Bed occupancy rate, median (IQR) & $85.7(79.9-92.3)$ & $85.7(76.0-92.3)$ & $86.7(77.8-92.3)$ & 0.040 \\
\hline Occupancy < 90\%, n (\%) & $7828(63.8)$ & $5141(64.2)$ & $2687(63.2)$ & 0.20 \\
\hline Occupancy $\geq 90 \%, n(\%)$ & $4177(34.1)$ & $2694(33.6)$ & $1483(34.9)$ & 0.20 \\
\hline \multicolumn{5}{|l|}{ Clustering of admissions, per bed ${ }^{d}$} \\
\hline Clustering admission per bed $<0.15$ & $10,252(83.6)$ & $6586(82.2)$ & $3666(86.2)$ & $<0.0001$ \\
\hline Clustering admission per bed $\geq 0.15$ & $2013(16.4)$ & $1428(17.8)$ & $585(13.8)$ & $<0.0001$ \\
\hline
\end{tabular}

ICU intensive care unit, IQR interquartile range, PACU postanesthetic care unit

a Unplanned admissions following bronchoscopy, endoscopy, cardiac catheterization, interventional radiology, etc.

'Patients' admission source classified by admitting physician as "other"

'Unspecified data points were unavailable in our database

${ }^{\mathrm{d}}$ Number of admissions in the $2 \mathrm{~h}$ before or after the index admission, divided by the number of funded ICU beds

\section{Sensitivity analyses}

Early morning admission occurring between 00:00 and 06:59 $\mathrm{h}$, between $00: 00$ and $06: 59 \mathrm{~h}$ on weekend/holidays, and between 00:00 and 06:59 $\mathrm{h}$ during winter months showed association with early death in the ICU (death within $30 \mathrm{~h}$ in the ICU) and shorter ICU LOS, likely driven by ICU survivors (Tables 4 and 5); however, admissions during these periods were not associated with total ICU or hospital mortality, or with hospital LOS (Table 5). 
Total admissions, all-cause ICU mortality, and afterhours mortality, stratified by ICU site

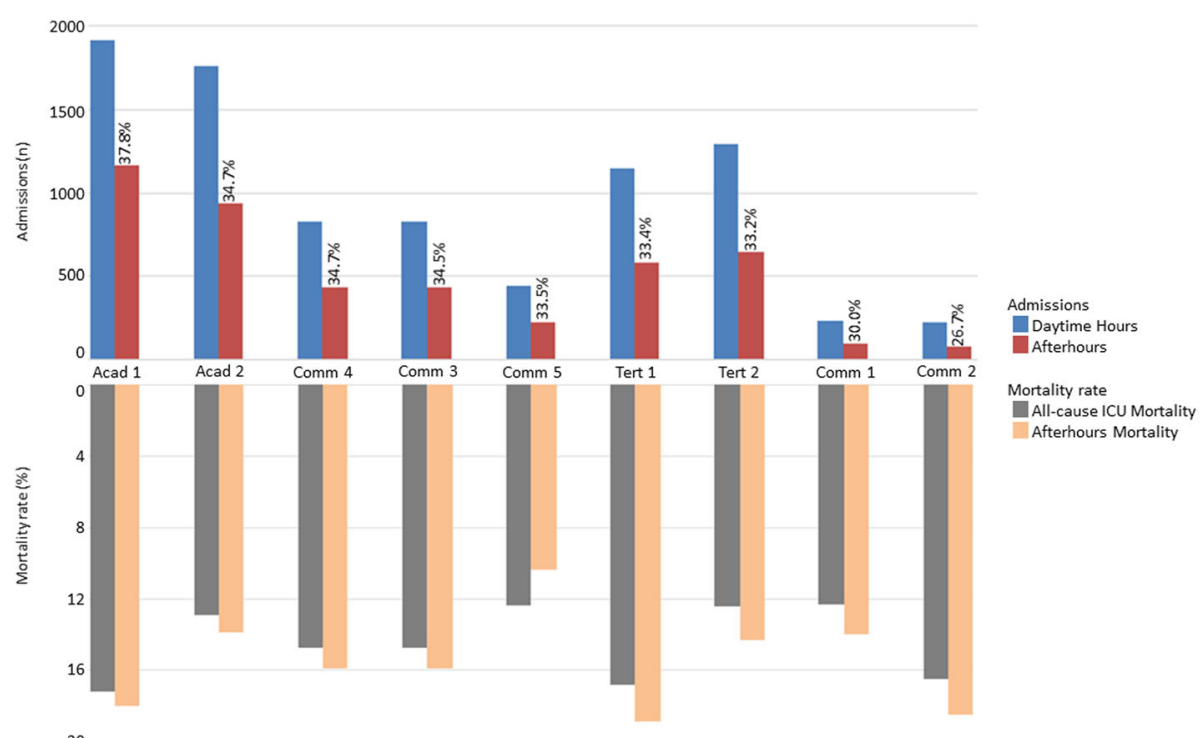

20

Fig. 1 Total admissions, all-cause ICU mortality, and afterhours mortality, stratified by ICU site. Site-specific total admissions ( $(n)$ and mortality (\%), stratified by daytime hours and afterhours admission time. Sites ordered (left to right) by decreasing proportion of afterhours admissions to total admissions, with percentage of total admissions occurring afterhours indicated numerically. Acad academic hospital, Comm community hospital, ICU intensive care unit, Tert tertiary hospital

\section{Discussion}

In this multicenter population-based cohort study in a large Canadian health region, we found that approximately one-third of all ICU admissions occurred afterhours. The proportion of afterhours admissions varied across sites, with a greater proportion occurring in academic hospital ICUs. Patients admitted afterhours were younger, had greater illness acuity, were more likely medical (non-operative), and were most commonly referred from the emergency department. We found no effect of afterhours admission on ICU or hospital mortality (either direct or after integrating effects mediated through illness severity); however, we showed that this effect may be sensitive to whether an ICU is experiencing strained capacity. Afterhours admission during periods of high occupancy was associated with increases in early ICU mortality and shorter ICU LOS, while concomitant clustering of admissions also showed association with early ICU mortality. Afterhours admission, including during periods of strain, was not, however, associated with greater all-cause hospital mortality.

\section{Interpretation with prior work}

Afterhours ICU admissions have shown inconsistent association with adverse patient outcomes when compared to admissions occurring during usual daytime hours. This variability is likely attributable to differences in study design, to varying definitions for "afterhours", heterogeneous case mix, differential risk of bias and residual confounding, type of health jurisdiction being evaluated, and, importantly, due to likely small estimates for differences in effect [20,21]. Two systematic reviews have suggested no incremental hazard for afterhours ICU admission and mortality risk; however, both suggested greater risk for admissions occurring on weekends relative to weekdays, and further suggested estimates may be sensitive to ICU organizational structure and geographic variation $[20$, 21]. In a large multicenter cohort study from Australia ( $n=245,057)$, afterhours (18:00-05:59 h) and weekend admissions were shown to have greater risk-adjusted hospital mortality compared with daytime admissions [27]. While mortality was marginally higher in our cohort and largely mediated by illness severity, our study adds new knowledge by suggesting that system-level variables such as strained capacity (i.e., high occupancy) and workload (i.e., clustering of ICU admissions), when coupled with admissions occurring afterhours, may further exert small but important effects on patient risk of adverse outcome.

A spectrum of system-related factors may account for the purported increased mortality risk associated with afterhours ICU admissions. ICU organizational structure, including reduced afterhours intensivist coverage and nurse-to-patient ratios, may negatively impact ICU care afterhours, particularly during strained capacity conditions [28]. Adoption of an in-house intensivist staffing model has shown variable effect to improve care processes and outcomes; however, no study has specifically evaluated how this coverage model performs during strain [29-34]. Similarly, greater bedside nursing workload may compromise care quality and increase the risk 
Table 2 Baseline patient characteristics, stratified by time of ICU admission

\begin{tabular}{|c|c|c|c|c|}
\hline Characteristic & $\begin{array}{l}\text { Total } \\
(n=12,265,100 \%)\end{array}$ & $\begin{array}{l}\text { Workhours } \\
(n=8014,65.3 \%)\end{array}$ & $\begin{array}{l}\text { Afterhours } \\
(n=4251,34.7 \%)\end{array}$ & $p$ value \\
\hline Age, median (IQR) & $59(46-70)$ & $60(47-70)$ & $58(44-70)$ & $<.0001$ \\
\hline Age category, $n(\%)$ & & & & 0.0022 \\
\hline$<65$ years & $7680(62.6)$ & 4934 (61.6) & $2746(64.6)$ & \\
\hline $65-74$ years & $2458(20.1)$ & $1674(20.9)$ & $784(18.5)$ & \\
\hline $75-84$ years & $1696(13.8)$ & $1132(14.1)$ & $564(13.3)$ & \\
\hline$\geq 85$ years & $426(3.5)$ & $270(3.4)$ & $156(3.7)$ & \\
\hline Sex, $n(\%)$ & & & & 0.29 \\
\hline Female & $5112(41.7)$ & $3367(42.0)$ & $1745(41.1)$ & \\
\hline Male & $7150(58.3)$ & $4644(58.0)$ & $2506(59.0)$ & \\
\hline System, n (\%) & & & & $<.0001$ \\
\hline Cardiovascular & $2103(17.3)$ & $696(16.5)$ & $696(16.5)$ & \\
\hline Gastrointestinal & $2044(16.8)$ & $677(16.0)$ & $677(16.0)$ & \\
\hline Genitourinary & 449 (3.7) & $136(3.2)$ & $136(3.2)$ & \\
\hline Hematology & $65(0.5)$ & $24(0.6)$ & $24(0.6)$ & \\
\hline Metabolic/endocrine & $246(2.0)$ & $85(2.0)$ & $85(2.0)$ & \\
\hline Musculoskeletal/skin & $485(4.0)$ & $144(3.4)$ & $144(3.4)$ & \\
\hline Neurologic & 1809 (14.9) & $679(16.1)$ & $679(16.1)$ & \\
\hline Respiratory & $3643(29.9)$ & $1216(28.8)$ & $1216(28.8)$ & \\
\hline Transplant & $129(1.1)$ & $52(1.2)$ & $52(1.2)$ & \\
\hline Trauma & $1211(9.9)$ & $519(12.3)$ & $519(12.3)$ & \\
\hline Surgery, n (\%) & & & & $<.0001$ \\
\hline Elective & $1209(9.9)$ & $962(12.0)$ & $247(5.8)$ & \\
\hline Emergent & $2054(16.8)$ & $1276(15.9)$ & 778 (18.3) & \\
\hline Nonoperative & 9002 (73.4) & $5776(72.1)$ & $3226(75.9)$ & \\
\hline Class, n (\%) & & & & $<.0001$ \\
\hline Medical & $7241(59.0)$ & $4701(58.7)$ & $2540(59.8)$ & \\
\hline Neurological & $851(6.9)$ & $501(6.3)$ & $350(8.2)$ & \\
\hline Surgical & $3101(25.3)$ & $2203(27.5)$ & $898(21.1)$ & \\
\hline Trauma without head injury & $647(5.3)$ & $379(4.7)$ & $268(6.3)$ & \\
\hline Trauma with head injury & $425(3.5)$ & $230(2.9)$ & $195(4.6)$ & \\
\hline \multicolumn{5}{|l|}{ Comorbidity disease, $n(\%)$} \\
\hline Chronic dialysis & $423(3.5)$ & $273(3.4)$ & $150(3.5)$ & 0.72 \\
\hline Hepatic & $1264(10.3)$ & $817(10.2)$ & $447(10.5)$ & 0.58 \\
\hline Neurologic & $5298(43.2)$ & $3303(41.2)$ & $1995(46.9)$ & $<.0001$ \\
\hline AIDS & $65(0.5)$ & $42(0.5)$ & $23(0.5)$ & 0.90 \\
\hline Chronic heart failure & $762(6.2)$ & $512(6.4)$ & $250(5.9)$ & 0.27 \\
\hline Respiratory & $1415(11.5)$ & $942(11.8)$ & $473(11.1)$ & 0.30 \\
\hline Metastatic/leukemia/lymphoma & $791(6.5)$ & $543(6.8)$ & $248(5.8)$ & 0.043 \\
\hline Immune suppression & $1095(8.9)$ & $736(9.2)$ & $359(8.5)$ & 0.17 \\
\hline Diabetes & $2280(18.6)$ & $1535(19.2)$ & $745(17.5)$ & 0.027 \\
\hline Cirrhosis & $785(6.4)$ & $526(6.6)$ & $259(6.1)$ & 0.31 \\
\hline Cardiovascular & $5752(46.9)$ & $3739(46.7)$ & $2013(47.4)$ & 0.47 \\
\hline Digestive & $2210(18.0)$ & $1449(18.1)$ & $761(17.9)$ & 0.80 \\
\hline
\end{tabular}


Table 2 Baseline patient characteristics, stratified by time of ICU admission (Continued)

\begin{tabular}{|c|c|c|c|c|}
\hline Characteristic & $\begin{array}{l}\text { Total } \\
(n=12,265,100 \%)\end{array}$ & $\begin{array}{l}\text { Workhours } \\
(n=8014,65.3 \%)\end{array}$ & $\begin{array}{l}\text { Afterhours } \\
(n=4251,34.7 \%)\end{array}$ & $p$ value \\
\hline Acute renal & $2869(23.4)$ & $1900(23.7)$ & $969(22.8)$ & 0.26 \\
\hline Charlson Index, median, (IQR) & $1(0-2)$ & $1(0-2)$ & $1(0-2)$ & $<.0001$ \\
\hline Admission APACHE II score, mean (SD) & $20.2(8.4)$ & $19.9(8.3)$ & $20.9(8.6)$ & $<.0001$ \\
\hline
\end{tabular}

AIDS acquired immune deficiency syndrome, APACHE acute physiology and chronic health evaluation, ICU intensive care unit, IQR interquartile range, SD standard deviation

of adverse outcomes [35]; however, no prior work has evaluated the relationship between afterhours admission and workload during strained conditions. Nursing workload may be susceptible to both patient-level factors (i.e., acuity) and system-level factors (i.e., reduced nurse-topatient ratios afterhours); and these relationships may be further exploited when ICUs become strained, such as during a large number of new admissions occurring within a relatively short period of time [36, 37].

\section{Implications for practice, research, and policy}

Our study supports the notion that both patient-specific and system-related factors may contribute to a small but important mortality risk associated with afterhours ICU admissions. While our work should be further replicated, it would imply at a minimum that individual ICUs and/or health regions should interrogate data on afterhours admissions, particularly during periods of strain. Future work should also examine for system-related patterns of strained ICU capacity that may be foreseeable, that may be further targets of quality improvement initiatives, and which could inform capacity and workforce planning, and policy development aimed at mitigating avoidable risk.

The greater acuity for afterhours admissions could be attributed to several factors, including patients whose ICU transfer was delayed or who received suboptimal initial resuscitation, more unplanned admissions (i.e., emergency surgery), or admission of sicker patients with reduced likelihood of deriving benefit from ICU care (i.e., futile ICU admission nearing end of life), due in part to different staffing models (i.e., no in-house intensivist coverage afterhours) [38]. These same factors may account for the higher early mortality occurring among afterhours admissions during periods of strain. The greater rates of afterhours admissions at academic sites in our study would support these hypotheses. Alternatively, Bhonagiri et al. [27] found greater mortality for afterhours admissions among elective surgery patients. This was speculated to occur due to delays in ICU admission from complicated intraoperative courses that were not otherwise captured in illness severity scores. In our cohort, however, elective surgical patients represented only $9.9 \%$ of ICU admissions and were consistently associated with reduced mortality in multivariate analysis [39].

\section{Limitations}

While our study was a relatively large multicenter population-based interrogation of routinely captured ICU clinical and administrative data, our study has limitations that warrant consideration. First, despite extensive covariate adjustment, our study is observational and remains susceptible to bias and residual confounding. Second, our cohort was restricted to those admitted to the ICU. We did not have data on patients who were referred to or received ICU consultation but were declined admission or those whose ICU admission was potentially

Table 3 Mortality and length of stay stratified by time of ICU admission

\begin{tabular}{|c|c|c|c|c|c|}
\hline Outcome & $\begin{array}{l}\text { Workhours } \\
(n=8014)\end{array}$ & $\begin{array}{l}\text { Afterhours } \\
(n=4251)\end{array}$ & Absolute difference & Unadjusted OR (95\% Cl) & $p$ value \\
\hline Death within 30 h $(n, \%)$ & $364(4.5 \%)$ & $238(5.6 \%)$ & $1.28 \%$ & $1.25(1.05-1.47)$ & 0.0099 \\
\hline Death within 3 days ( $n, \%)$ & $585(7.3 \%)$ & $371(8.7 \%)$ & $1.43 \%$ & $1.21(1.06-1.39)$ & 0.0050 \\
\hline Death within 7 days $(n, \%)$ & $771(9.6 \%)$ & $495(11.6 \%)$ & $2.02 \%$ & $1.24(1.10-1.40)$ & 0.0005 \\
\hline Death in ICU $(n, \%)$ & $1127(14.1 \%)$ & $675(15.9 \%)$ & $1.82 \%$ & $1.15(1.04-1.28)$ & 0.0069 \\
\hline Death in hospital $(n, \%)$ & $1670(20.8 \%)$ & $935(22.0 \%)$ & $1.16 \%$ & $1.07(0.98-1.17)$ & 0.14 \\
\hline LOS in ICU, days (median (IQR)) & $3.7(1.9-7.4)$ & $3.6(1.7-7.5)$ & -0.1 & - & 0.42 \\
\hline LOS in ICU for survivors (median (IQR)) & $3.8(1.9-7.3)$ & $3.7(1.8-7.6)$ & -0.1 & - & 0.68 \\
\hline LOS in ICU for non-survivors (median (IQR)) & $2.6(0.9-7.6)$ & $2.4(0.7-6.1)$ & -0.2 & - & 0.039 \\
\hline LOS in hospital, days (median (IQR)) & $14(6-30)$ & $13(5-28)$ & -1.0 & - & 0.0006 \\
\hline
\end{tabular}

Cl confidence interval, ICU intensive care unit, IQR interquartile range, LOS length of stay, OR odds ratio 
ICU Admission and APACHE II Score Predicted and Observed ICU Mortality, Stratified By Hour of Admission

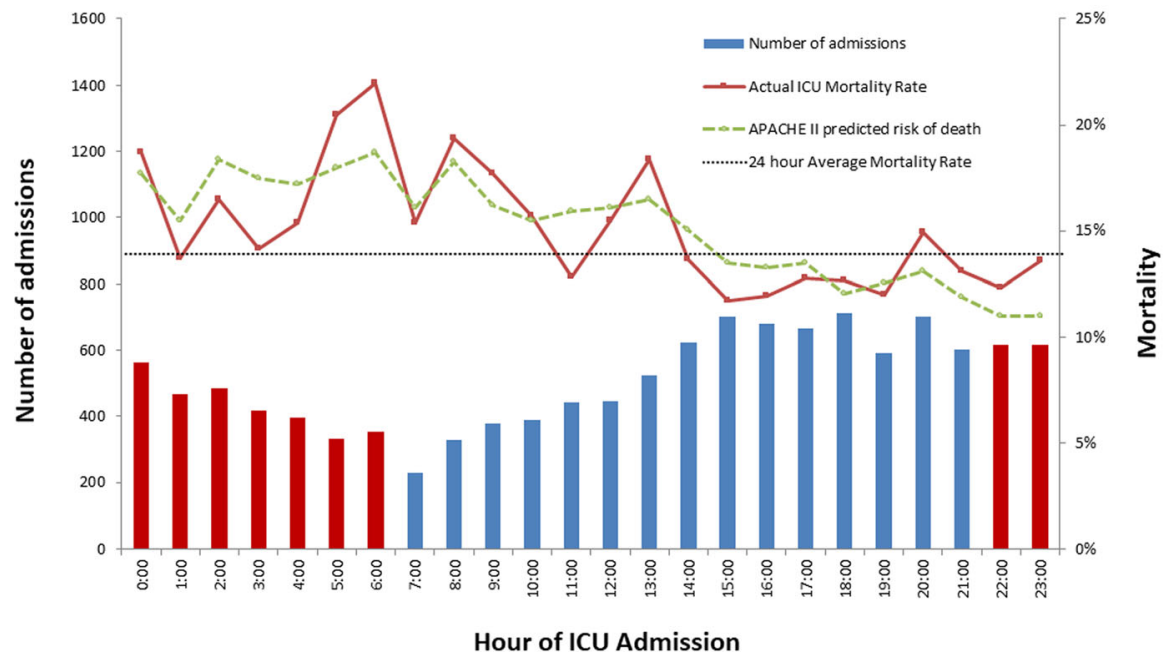

Fig. 2 ICU admission and APACHE II score predicted and observed mortality rates, stratified by hour of ICU admission. Histogram demonstrating number of admissions by hour with red and blue bars representing afterhours and daytime hours, respectively. Line graph shows APACHE ॥ predicted risk of death, with superimposed actual ICU mortality rate, by hour. APACHE Acute Physiology And Chronic Health Evaluation, ICU intensive care unit

delayed [40, 41]. Similarly, we did not have data on patient goals of care at the time of ICU admission or changes that occurred thereafter, recognizing their potential interaction with strained capacity [42]. Third, we defined afterhours admission as occurring between 22:00 and 06:59 h to largely reflect contemporaneous practice in our health region; and while we applied a variety of sensitivity analyses to this definition, we recognize this may not be generalizable to other jurisdictions with variable ICU organization structures.
Fourth, our study focused on relatively proximate patient outcomes occurring in the ICU and hospital; as such, we cannot comment on alternative outcomes that may be associated with afterhours ICU admission including major morbidity, satisfaction with care, and long-term mortality.

\section{Conclusions}

Afterhours ICU admission is common and associated with increased illness severity. Although afterhours

Table 4 Summary of direct, indirect, and total (integrated) effect of afterhours admission on ICU mortality, hospital mortality, and lengths of stay

\begin{tabular}{|c|c|c|c|c|c|c|}
\hline \multirow[t]{2}{*}{ Outcome } & \multicolumn{2}{|l|}{ Direct effect } & \multicolumn{2}{|l|}{ Indirect effect } & \multicolumn{2}{|c|}{ Total (integrated effect) } \\
\hline & OR $(95 \% \mathrm{Cl})$ & $p$ value & OR $(95 \% \mathrm{Cl})$ & $p$ value & OR $(95 \% \mathrm{Cl})$ & $p$ value \\
\hline \multicolumn{7}{|l|}{ Mortality } \\
\hline Death in ICU & $0.96(0.87-1.06)$ & 0.39 & $1.07(1.05-1.09)$ & $<.0001$ & $1.02(0.92-1.14)$ & 0.66 \\
\hline Death within $30 \mathrm{~h}$ in ICU & $1.00(0.83-1.22)$ & 0.97 & $1.11(1.07-1.14)$ & $<.0001$ & $1.11(0.91-1.35)$ & 0.30 \\
\hline Death within 3 days in ICU & $0.97(0.83-1.14)$ & 0.74 & $1.09(1.06-1.12)$ & $<.0001$ & $1.06(0.91-1.24)$ & 0.46 \\
\hline Death within 7 days in ICU & $1.01(0.88-1.15)$ & 0.94 & $1.08(1.06-1.11)$ & $<.0001$ & $1.09(0.95-1.24)$ & 0.21 \\
\hline Death in hospital & $0.94(0.86-1.03)$ & 0.21 & $1.05(1.04-1.07)$ & $<.0001$ & $0.99(0.91-1.09)$ & 0.89 \\
\hline \multicolumn{7}{|l|}{ Length of stay } \\
\hline LOS in ICU & $0.93(0.88-0.98)$ & 0.013 & $1.02(1.01-1.02)$ & $<.0001$ & $0.94(0.89-1.00)$ & 0.0498 \\
\hline LOS in ICU for survivors & $0.94(0.90-0.98)$ & 0.0024 & $1.03(1.02-1.04)$ & $<.0001$ & $0.97(0.93-1.01)$ & 0.11 \\
\hline LOS in ICU for nonsurvivors & $1.02(0.85-1.21)$ & 0.86 & $0.97(0.96-0.98)$ & $<.0001$ & $0.98(0.83-1.17)$ & 0.86 \\
\hline LOS in hospital & $0.96(0.90-1.02)$ & 0.20 & $1.01(1.00-1.01)$ & 0.021 & $0.96(0.90-1.03)$ & 0.27 \\
\hline
\end{tabular}

OR estimates and their $95 \%$ Cls were calculated based on parameter estimates; parameter estimates of integrated effect were based on 1 million times simulation experiments Cl confidence interval, ICU intensive care unit, LOS length of stay, OR odds ratio 
Table 5 Sensitivity analysis demonstrating the integrated effect of various admission times and admission conditions on ICU mortality, hospital mortality, and length of stay

\begin{tabular}{|c|c|c|c|c|c|c|}
\hline \multirow[t]{2}{*}{ Outcome } & \multicolumn{2}{|c|}{ Between 00:00 and 06:59h } & \multicolumn{2}{|c|}{$\begin{array}{l}\text { Between } 00: 00 \text { and } 06: 59 \mathrm{~h} \\
\text { on non-work day }\end{array}$} & \multicolumn{2}{|c|}{$\begin{array}{l}\text { Between } 00: 00 \text { and } 06: 59 \mathrm{~h} \\
\text { and during October-March }\end{array}$} \\
\hline & OR (95\% Cl) & $p$ value & OR $(95 \% \mathrm{Cl})$ & $p$ value & OR (95\% Cl) & $p$ value \\
\hline \multicolumn{7}{|l|}{ Mortality } \\
\hline Death in ICU & $1.10(0.98-1.23)$ & 0.10 & $1.13(0.96-1.34)$ & 0.14 & $1.15(0.99-1.33)$ & 0.060 \\
\hline Death within $30 \mathrm{~h}$ in ICU & $1.28(1.03-1.58)$ & 0.024 & $1.44(1.07-1.94)$ & 0.018 & $1.38(1.06-1.80)$ & 0.016 \\
\hline Death within 3 days in ICU & $1.17(0.98-1.39)$ & 0.075 & $1.34(1.04-1.72)$ & 0.023 & $1.37(1.11-1.70)$ & 0.0039 \\
\hline Death within 7 days in ICU & $1.14(0.98-1.31)$ & 0.091 & $1.34(1.09-1.66)$ & 0.0068 & $1.23(1.02-1.49)$ & 0.028 \\
\hline Death in hospital & $1.02(0.92-1.13)$ & 0.70 & $1.08(0.93-1.26)$ & 0.33 & $1.13(0.99-1.29)$ & 0.065 \\
\hline \multicolumn{7}{|l|}{ Length of stay } \\
\hline LOS in ICU & $0.80(0.66-0.97)$ & 0.026 & $0.80(0.67-0.94)$ & 0.0084 & $0.89(0.72-1.09)$ & 0.26 \\
\hline \multirow[t]{3}{*}{ LOS in hospital } & $1.01(0.85-1.20)$ & 0.91 & $0.94(0.81-1.10)$ & 0.43 & $0.98(0.82-1.16)$ & 0.78 \\
\hline & \multicolumn{2}{|c|}{$\begin{array}{l}\text { Between 00:00 and 06:59 h } \\
\text { and bed occupancy } \geq 90 \%\end{array}$} & \multicolumn{2}{|c|}{$\begin{array}{l}\text { Between 00:00 and 06:59 } \mathrm{h} \\
\text { and bed occupancy } \geq 95 \%\end{array}$} & \multicolumn{2}{|c|}{$\begin{array}{l}\text { Afterhours and clustering } \\
\text { admissions per bed } \geq 0.15\end{array}$} \\
\hline & OR $(95 \% \mathrm{Cl})$ & $p$ value & OR $(95 \% \mathrm{Cl})$ & $p$ value & OR $(95 \% \mathrm{Cl})$ & $p$ value \\
\hline \multicolumn{7}{|l|}{ Mortality } \\
\hline Death in ICU & $1.21(1.03-1.43)$ & 0.019 & $1.26(1.01-1.58)$ & 0.039 & $1.08(0.97-1.20)$ & 0.15 \\
\hline Death within $30 \mathrm{~h}$ in ICU & $1.37(1.02-1.85)$ & 0.037 & $1.34(0.88-2.03)$ & 0.18 & $1.25(1.02-1.53)$ & 0.030 \\
\hline Death within 3 days in ICU & $1.33(1.04-1.69)$ & 0.021 & $1.26(0.91-1.76)$ & 0.17 & $1.18(1.00-1.38)$ & 0.049 \\
\hline Death within 7 days in ICU & $1.25(1.01-1.54)$ & 0.039 & $1.24(0.93-1.66)$ & 0.15 & $1.16(1.01-1.33)$ & 0.034 \\
\hline Death in hospital & $1.11(0.96-1.29)$ & 0.17 & $1.12(0.91-1.37)$ & 0.28 & $1.05(0.95-1.15)$ & 0.33 \\
\hline \multicolumn{7}{|l|}{ Length of stay } \\
\hline LOS in ICU & $0.79(0.63-0.98)$ & 0.031 & $0.97(0.91-1.03)$ & 0.26 & $0.94(0.89-1.01)$ & 0.083 \\
\hline LOS in hospital & $1.08(0.88-1.33)$ & 0.46 & $1.02(0.90-1.16)$ & 0.72 & $0.97(0.90-1.04)$ & 0.32 \\
\hline
\end{tabular}

OR estimates and their $95 \%$ Cls were calculated based on parameter estimates; parameter estimates of integrated effect were based on 1 million times simulation experiments

$\mathrm{Cl}$ confidence interval, ICU intensive care unit, LOS length of stay, OR odds ratio

ICU admission did not portend greater mortality risk in most circumstances, this association may be sensitive to strained ICU capacity conditions. Future work should focus on evaluating those modifiable factors, particularly if related to ICU organizational structure that may mediate mortality risk associated with afterhours ICU admission.

\section{Additional files}

Additional file 1: Summary of path-analysis modeling strategy. (DOCX $33 \mathrm{~kb}$ )

Additional file 2: Multivariate, mixed-effects linear regression of factors associated with admission APACHE II score. (DOCX $20 \mathrm{~kb}$ )

Additional file 3: Multivariate, mixed-effects logistic regression on ICU mortality within $30 \mathrm{~h}$. (DOCX $21 \mathrm{~kb})$

Additional file 4: Multivariate, mixed-effects logistic regression on ICU mortality within 3 days. (DOCX 21 kb)

Additional file 5: Multivariate, mixed-effects logistic regression on ICU mortality within 7 days. (DOCX $21 \mathrm{~kb}$ )

Additional file 6: Multivariate, mixed-effects logistic regression on ICU mortality. (DOCX 22 kb)
Additional file 7: Multivariate, mixed effects logistic regression on hospital mortality. (DOCX $21 \mathrm{~kb}$ )

Additional file 8: Direct effects of admission APACHE II score on ICU mortality, hospital mortality, and length of stay. (DOCX 18 kb)

Additional file 9: Multivariate, mixed-effects Poisson regression model for hospital length of stay. (DOCX $20 \mathrm{~kb}$ )

\section{Abbreviations}

AIDS: Acute immunodeficiency syndrome; APACHE II: Acute Physiology and Chronic Health Evaluation II; Cl: Confidence interval; ED: Emergency department; ICU: Intensive care unit; IQR: Interquartile range; LOS: Length of stay; OR: Odds ratio; SD: Standard deviation; SE: Standard error

\section{Funding}

This work was funded by a Partnership for Research and Innovation in the Health System (PRIHS) grant, Alberta Innovates-Health Solutions (Grant Record Number: 201300467). The funding agency had no role in the design or conduct of the study, in the collection, management, analysis, or interpretation of the data, or in the preparation, review, or approval of the manuscript.

\section{Availability of data and materials}

The data to support this study were provided by the eCritical Program and Alberta Health Services. Data are available from the authors upon reasonable request and with permission of Alberta Health Services. 


\section{Authors' contributions}

AMH analyzed data, interpreted data, and drafted the manuscript with support from SMB, and provided critical revision of the manuscript. HTS conceived the study, obtained funding for the study, interpreted data, and provided critical revision of the manuscript. XW analyzed the data, performed the simulation experiments, interpreted data, and provided critical revision of the manuscript. GC obtained data, interpreted the data, and provided critical revision of the manuscript. DJZ obtained data, interpreted data, and provided critical revision of the manuscript. PD interpreted data and provided critical revision of the manuscript. AG interpreted data and provided critical revision of the manuscript. DCS interpreted data and provided critical revision of the manuscript. LB interpreted data and provided critical revision of the manuscript. DAZ interpreted data and provided critical revision of the manuscript. SMB conceived the study, obtained funding for the study, obtained data, analyzed the data, interpreted data, and provided critical revision of the manuscript. All authors read and approved the final manuscript.

\section{Authors' information}

SMB is supported by a Canada Research Chair in Critical Care Nephrology. HTS is supported by a CIHR Embedded Clinician Researcher Award.

\section{Ethics approval and consent to participate}

This study was approved by the Health Research Ethics Board at the University of Alberta prior to commencement (File \# Pro00046184). The need for written informed consent was waived.

\section{Competing interests}

The authors declare that they have no competing interests.

\section{Publisher's Note}

Springer Nature remains neutral with regard to jurisdictional claims in published maps and institutional affiliations.

\section{Author details}

'Department of Critical Care Medicine, Faculty of Medicine and Dentistry, University of Alberta and Alberta Health Services, 2-124E Clinical Sciences Building, 8440-112 ST NW, Edmonton T6G 2B7, Canada. ${ }^{2}$ Department of Critical Care Medicine, Cumming School of Medicine, University of Calgary and Alberta Health Services, Calgary, Canada. ${ }^{3}$ Critical Care Strategic Clinical Network, Alberta Health Services, Edmonton, Canada. ${ }^{4}$ Research Facilitation, Research Analytics (DIMR), Alberta Health Services, Edmonton, Canada. ${ }^{5}$ Division of Critical Care Medicine and Center for Health Evaluation and Outcome Sciences, St. Paul's Hospital and University of British Columbia, Vancouver, Canada. ${ }^{6}$ Section of Critical Care Medicine, Department of Medicine, University of Manitoba, Winnipeg, Canada. ${ }^{7}$ Department of Critical Care Medicine, University of Toronto and Sunnybrook Health Sciences Centre, Toronto, Canada.

Received: 26 January 2018 Accepted: 3 April 2018

Published online: 17 April 2018

\section{References}

1. Rivers E, Nguyen B, Havstad S, Ressler J, Muzzin A, Knoblich B, Peterson E, Tomlanovich M. Early goal-directed therapy in the treatment of severe sepsis and septic shock. N Engl J Med. 2001;345(19):1368-77.

2. Boersma E, Maas AC, Deckers JW, Simoons ML. Early thrombolytic treatment in acute myocardial infarction: reappraisal of the golden hour. Lancet. 1996; 348(9030):771-5.

3. Dimopoulos K, Dudek D, Piscione F, Mielecki W, Savonitto S, Borgia F, Murena E, Manari A, Gaspardone A, Ochala A, Zmudka K, Bolognese L, Steg PG, Flather M, Di Mario C. Timing of events in STEMl patients treated with immediate PCI or standard medical therapy: implications on optimisation of timing of treatment from the CARESS-in-AMI trial. Int J Cardiol. 2012;154(3):275-81.

4. Hacke W, Donnan G, Fieschi C, Kaste M, von Kummer R, Broderick JP, Brott T, Frankel M, Grotta JC, Haley EC, Kwiatkowski T, Levine SR, Lewandowski C, Lu M, Lyden P, Marler JR, Patel S, Tilley BC, Albers G, Bluhmki E, Wilhelm M, Hamilton S. Association of outcome with early stroke treatment: pooled analysis of ATLANTIS, ECASS, and NINDS rt-PA stroke trials. Lancet. 2004; 363(9411):768-74.

5. Emberson J, Lees KR, Lyden P, Blackwell L, Albers G, Bluhmki E, Brott T, Cohen G, Davis S, Donnan G, Grotta J, Howard G, Kaste M, Koga M, von Kummer R,
Lansberg M, Lindley RI, Murray G, Olivot JM, Parsons M, Tilley B, Toni D, Toyoda K, Wahlgren N, Wardlaw J, Whiteley W, del Zoppo GJ, Baigent C, Sandercock P, Hacke W. Effect of treatment delay, age, and stroke severity on the effects of intravenous thrombolysis with alteplase for acute ischaemic stroke: a meta-analysis of individual patient data from randomised trials. Lancet. 2014;384(9958):1929-35.

6. Howard JT, Kotwal RS, Santos AR, Martin MJ, Stockinger ZT. Re-examination of a Battlefield Trauma Golden Hour Policy. J Trauma Acute Care Surg. 2018; 84(1):11-18.

7. Stub D, Bernard S, Pellegrino V, Smith K, Walker T, Sheldrake J, Hockings L, Shaw J, Duffy SJ, Burrell A, Cameron P, Smit DV, Kaye DM. Refractory cardiac arrest treated with mechanical CPR, hypothermia, ECMO and early reperfusion (the CHEER trial). Resuscitation. 2015;86:88-94.

8. Neumar RW, Shuster M, Callaway CW, Gent LM, Atkins DL, Bhanji F, Brooks SC, de Caen AR, Donnino MW, Ferrer JME, Kleinman ME, Kronick SL, Lavonas EJ, Link MS, Mancini ME, Morrison L, O'Connor RE, Samson RA, Schexnayder SM, Singletary EM, Sinz EH, Travers AH, Wyckoff MH, Hazinski MF. Part 1: Executive Summary: 2015 American Heart Association Guidelines Update for Cardiopulmonary Resuscitation and Emergency Cardiovascular Care. Circulation. 2015;132(18 Suppl 2):315.

9. Nates JL, Nunnally M, Kleinpell R, Blosser S, Goldner J, Birriel B, Fowler CS, Byrum D, Miles WS, Bailey H, Sprung CL. ICU admission, discharge, and triage guidelines: a framework to enhance clinical operations, development of institutional policies, and further research. Crit Care Med. 2016;44(8):1553-602.

10. Simchen E, Sprung CL, Galai N, Zitser-Gurevich Y, Bar-Lavi Y, Gurman G, Klein M, Lev A, Levi L, Zveibil F, Mandel M, Mnatzaganian G. Survival of critically ill patients hospitalized in and out of intensive care units under paucity of intensive care unit beds. Crit Care Med. 2004;32(8):1654-61.

11. Chalfin DB, Trzeciak S, Likourezos A, Baumann BM, Dellinger RP. Impact of delayed transfer of critically ill patients from the emergency department to the intensive care unit. Crit Care Med. 2007;35(6):1477-83.

12. Obel N, Schierbeck J, Pedersen L, Storgaard M, Sorensen HT, Hansen B. Mortality after discharge from the intensive care unit during the early weekend period: a population-based cohort study in Denmark. Acta Anaesthesiol Scand. 2007;51(9):1225-30.

13. Goldfrad C, Rowan K. Consequences of discharges from intensive care at night. Lancet. 2000;355(9210):1138-42.

14. Duke GJ, Green JV, Briedis JH. Night-shift discharge from intensive care unit increases the mortality-risk of ICU survivors. Anaesth Intensive Care. 2004; 32(5):697-701.

15. Pilcher DV, Duke GJ, George C, Bailey MJ, Hart G. After-hours discharge from intensive care increases the risk of readmission and death. Anaesth Intensive Care. 2007;35(4):477-85.

16. Priestap F, Martin C. Impact of intensive care unit discharge time on patient outcome. Crit Care Med. 2006;34(12):2946-51.

17. Barnett MJ, Kaboli PJ, Sirio CA, Rosenthal GE. Day of the week of intensive care admission and patient outcomes: a multisite regional evaluation. Med Care. 2002;40(6):530-9.

18. Uusaro A, Kari A, Ruokonen E. The effects of ICU admission and discharge times on mortality in Finland. Intensive Care Med. 2003;29(12):2144-8.

19. Laupland KB, Shahpori R, Kirkpatrick AW, Stelfox HT. Hospital mortality among adults admitted to and discharged from intensive care on weekends and evenings. J Crit Care. 2008;23(3):317-24.

20. Cavallazzi R. Association between time of admission to the ICU and mortality: a systematic review and metaanalysis. Chest. 2010;138(1):68.

21. Galloway M, Hegarty A, McGill S, Arulkumaran N, Brett SJ, Harrison D. The effect of ICU out-of-hours admission on mortality: a systematic review and meta-analysis. Crit Care Med. 2017;

22. Bagshaw SM, Wang X, Zygun DA, Zuege D, Dodek P, Garland A, Scales DC, Berthiaume L, Faris P, Chen G, Opgenorth D, Stelfox HT. Association between strained capacity and mortality among patients admitted to intensive care: a path-analysis modeling strategy. J Crit Care. 2017;43:81-7.

23. Stelfox HT, Hemmelgarn BR, Bagshaw SM, Gao S, Doig CJ, Nijssen-Jordan C, Manns B. Intensive care unit bed availability and outcomes for hospitalized patients with sudden clinical deterioration. Arch Intern Med. 2012;172(6):467-74

24. Stelfox HT, Ahmed SB, Zygun D, Khandwala F, Laupland K. Characterization of intensive care unit acquired hyponatremia and hypernatremia following cardiac surgery. Can J Anaesth. 2010;57(7):650-8.

25. Hicks R, Tingley D. Causal Mediation Analysis. Stata J. 2011;11(4):605-19.

26. R Core Team. R: Language for Statistical Computing: R Foundation for Statistical Computing; 2013 (available at: https://www.r-project.org/; date accessed: Jan 26 2018). 
27. Bhonagiri D, Pilcher DV, Bailey MJ. Increased mortality associated with afterhours and weekend admission to the intensive care unit: a retrospective analysis. Med J Aust. 2011;194(6):287.

28. Garland A, Gershengorn HB. Staffing in ICUs: physicians and alternative staffing models. Chest. 2013;143(1):214-21.

29. Benoit MA, Bagshaw SM, Norris CM, Zibdawi M, Chin WD, Ross DB, van Diepen S. Postoperative complications and outcomes associated with a transition to 24/7 intensivist management of cardiac surgery patients. Crit Care Med. 2017:45(6):993-1000.

30. Wilcox M, Chong CAK, Niven D, Rubenfeld G, Rowan K, Wunsch H, Fan E. Do intensivist staffing patterns influence hospital mortality following ICU admission? A systematic review and meta-analyses. Crit Care Med. 2013;41(10):2253-74.

31. Arabi Y, Alshimemeri A, Taher S. Weekend and weeknight admissions have the same outcome of weekday admissions to an intensive care unit with onsite intensivist coverage. Crit Care Med. 2006:34(3):605-11.

32. Kerlin MP, Small DS, Cooney E, Fuchs BD, Bellini LM, Mikkelsen ME, Schweickert WD, Bakhru RN, Gabler NB, Harhay MO, Hansen-Flaschen J, Halpern SD. A randomized trial of nighttime physician staffing in an intensive care unit. $\mathrm{N}$ Engl J Med. 2013;368(23):2201.

33. Wallace DJ, Angus DC, Barnato AE, Kramer AA, Kahn JM. Nighttime intensivist staffing and mortality among critically ill patients. N Engl J Med. 2012:366(22):2093-101.

34. Laupland KB, Misset B, Souweine B, Tabah A, Azoulay E, Goldgran-Toledano D, Dumenil A, Vésin A, Jamali S, Kallel H, Clec'h C, Darmon M, Schwebel C, Timsit J. Mortality associated with timing of admission to and discharge from ICU: a retrospective cohort study. BMC Health Serv Res. 2011;11(1):321.

35. Daud-Gallotti RM, Costa SF, Guimarães T, Padilha KG, Inoue EN, Vasconcelos TN, da Silva Cunha Rodrigues F, Barbosa EV, Figueiredo WB, Levin AS. Nursing workload as a risk factor for healthcare associated infections in ICU: a prospective study. PLoS One. 2012;7(12):e52342.

36. Debergh DP, Myny D, Van Herzeele I, Van Maele G, Reis Miranda D, Colardyn F. Measuring the nursing workload per shift in the ICU. Intensive Care Med. 2012;38(9):1438-44.

37. Altafin JAM, Grion CMC, Tanita MT, Festti J, Cardoso LTQ, Veiga CFF, Kamiji D, Barbosa ÁRG, Matsubara CCT, Lara AB, Lopes CCB, Blum D, Matsuo T. Nursing Activities Score and workload in the intensive care unit of a university hospital. Revista Brasileira de terapia intensiva. 2014;26(3):292.

38. Bagshaw SM, Opgenorth D, Potestio M, Hastings SE, Hepp SL, Gilfoyle E, McKinlay D, Boucher P, Meier M, Parsons-Leigh J, Gibney RTN, Zygun DA, Stelfox HT. Healthcare provider perceptions of causes and consequences of ICU capacity strain in a large publicly funded integrated health region: a qualitative study. Crit Care Med. 2017;45(4):e356.

39. Afessa B. Association between ICU admission during morning rounds and mortality. Chest. 2009;136(6):1489-95.

40. Robert R, Reignier J, Tournoux-Facon C, Boulain T, Lesieur O, Gissot V, Souday V, Hamrouni M, Chapon C, Gouello J. Refusal of intensive care unit admission due to a full unit: impact on mortality. Am J Respir Crit Care Med. 2012;185(10):1081-7.

41. Cardoso LTQ, Grion CMC, Matsuo T, Anami EHT, Kauss IAM, Seko L, Bonametti AM. Impact of delayed admission to intensive care units on mortality of critically ill patients: a cohort study. Crit Care. 2011;15(1):R28.

42. Hua M, Halpern SD, Gabler NB, Wunsch H. Effect of ICU strain on timing of limitations in life-sustaining therapy and on death. Intensive Care Med. 2016;42(6):987-94.

\section{Ready to submit your research? Choose BMC and benefit from:}

- fast, convenient online submission

- thorough peer review by experienced researchers in your field

- rapid publication on acceptance

- support for research data, including large and complex data types

- gold Open Access which fosters wider collaboration and increased citations

- maximum visibility for your research: over $100 \mathrm{M}$ website views per year

At BMC, research is always in progress.

Learn more biomedcentral.com/submissions 